\title{
Mortality and causes of death in 398 patients admitted to hospital with ankylosing spondylitis
}

\author{
Kari Lehtinen
}

\begin{abstract}
The mortality and causes of death in 398 patients (47 women, 351 men) with definite ankylosing spondylitis, admitted to hospital for the first time between 1961 and 1969, were investigated. The mean age at first admission was $36 \cdot 5$ years (SD 11.8). After a mean follow up time of $25 \cdot 7$ years, a total of 152 patients ( 12 women, 140 men) had died. The expected mortality based on the mortality statistics of the general population of the same sex and age was $103.1(9.4$ women and 93.7 men). Thus the overall mortality of the patients with ankylosing spondylitis was $\mathbf{1 . 5}$ times that expected. Those patients who had died were significantly older, had a higher erythrocyte sedimentation rate, and more inflamed peripheral joints when first seen than the surviving patients. The main difference between the observed and expected causes of death was the high incidence of deaths from ankylosing spondylitis, which was the underlying cause of death in 27 patients. The mechanism of death in these patients was secondary amyloidosis in 19, cardiovascular complications in six, fracture of the spine in one, and it was not known in one patient. Excess deaths due to circulatory, gastrointestinal and renal diseases, and violence were also observed.
\end{abstract}

(Ann Rheum Dis 1993; 52: 174-176)

In a few studies published in the 1950 s it was stated that ankylosing spondylitis is a benign disease with no excess mortality. ${ }^{12}$ Since then it has been shown that the mortality of patients given radiographic treatment is 1.8 times greater than expected, ${ }^{3}$ and that the mortality of those patients given only one course of radiological treatment is 1.7 times greater than expected. ${ }^{4}$ In another study, the mortality of those patients with ankylosing spondylitis not given radiological treatment was $60 \%$ greater than that of the control group. ${ }^{5} \mathrm{~A}$ clear difference has been found between the mortality of patients given radiological treatment and those not given it, to the benefit of the latter group. ${ }^{6}$ In general, studies conducted in the $1970 \mathrm{~s}$ and $1980 \mathrm{~s}$ have concluded that given a follow up time of 20-30 years, the mortality of patients with ankylosing spondylitis is $1.6-1.9$ times higher than that of the general population. ${ }^{1245}$
Secondary amyloidosis has been considered a rare complication of ankylosing spondylitis, ${ }^{78}$ with hardly any clinical importance. ${ }^{9}$ As early as 1960, however, amyloidosis was found in $6 \%$ of dead patients with ankylosing spondylitis, ${ }^{10}$ and in the 1970 s the prevalence of secondary amyloidosis in ankylosing spondylitis was estimated to be from 4.4 to $8 \cdot 6 \% .{ }^{11-13}$ In an earlier study the present author found amyloidosis to be a direct cause of death in 14 of $79(18 \%)$ patients with ankylosing spondylitis. ${ }^{14}$

The purpose of this study was to establish the mortality and causes of death in patients with ankylosing spondylitis, with a special interest in amyloidosis, using a larger patient sample than in the earlier study, ${ }^{14}$ and thus either to confirm or disprove the earlier finding of the high prevalence of secondary amyloidosis in Finnish patients with ankylosing spondylitis.

\section{Patients and methods}

Patients with ankylosing spondylitis treated for the first time at the Rheumatism Foundation Hospital in 1961-9 were eligible for the study. A total of 398 patients ( 351 men, 47 women) were studied. The radiographs and records of all patients were analysed. All patients fulfilled the diagnostic criteria of 'definite' ankylosing spondylitis accepted at the WHO meeting in New York in 1967. The number of deaths and causes of death were obtained from official death statistics of the Central Statistical Office of Finland. It was also established whether the causes of death were ascertained at necropsy, during operation, by histological examination, or otherwise.

The Central Statistical Office also calculated the expected mortality and causes of death of Finnish people with corresponding sex and date of birth, and the same follow up time as the study population. The mean follow up time was $25 \cdot 7$ years.

In the statistical analysis of living and dead patients, the $t$ test and Mann-Whitney test were used. When corresponding $p$ values were smaller than 0.01 , the results were considered significant.

Table 1 gives details of the study group.

\section{Results}

At the end of the follow up 140 male and 12 female patients had died, whereas the expected numbers of deaths were 93.7 for men, 9.4 for 
Table 1 Characteristics of the study group

\begin{tabular}{llll}
\hline & $\begin{array}{l}\text { Men } \\
(n=351)\end{array}$ & $\begin{array}{l}\text { Women } \\
(n=47)\end{array}$ & $\begin{array}{l}\text { All patients } \\
(n=398)\end{array}$ \\
\hline Mean (SD) age at the onset of symptoms (years) & $\begin{array}{l}28 \cdot 5(9 \cdot 6) \\
\text { Mean (SD) age at the beginning of follow up (years) }\end{array}$ & $\begin{array}{l}36 \cdot 0(11 \cdot 7) \\
40 \cdot 4(11.6)\end{array}$ & $\begin{array}{l}28 \cdot 8(9 \cdot 5) \\
36 \cdot 5(11 \cdot 8)\end{array}$ \\
\hline
\end{tabular}

Table 2 Underlying causes of death. Values are number (\%) of patients

\begin{tabular}{lccc}
\hline Cause of death & Observed & Expected & $\begin{array}{c}\text { Observed/ } \\
\text { expected }\end{array}$ \\
\hline ICD I Infections & $2(1)$ & $1 \cdot 2(1)$ & $1 \cdot 7$ \\
ICD II Malignant neoplasms & $19(13)$ & $20 \cdot 2(20)$ & 0.9 \\
ICD III Endocrinological, nutritional and metabolic & $1(1)$ & $1 \cdot 1(1)$ & 0.9 \\
$\quad$ diseases & 0 & $0 \cdot 2(0 \cdot 2)$ & \\
ICD IV Diseases of blood and blood forming organs & $1(1)$ & $1 \cdot 1(1)$ & 0.9 \\
ICD VI Neurological diseases & $64(42)$ & $52 \cdot 9(51)$ & $1 \cdot 2$ \\
ICD VII Circulatory diseases & $9(6)$ & $7 \cdot 5(7)$ & $1 \cdot 2$ \\
ICD VIII Respiratory diseases & $9(6)$ & $2 \cdot 6(3)$ & 3.5 \\
ICD IX Gastrointestinal diseases & $4(3)$ & $1 \cdot 6(2)$ & $2 \cdot 5$ \\
ICD X Renal diseases & $27(18)$ & $0 \cdot 3(0 \cdot 3)$ & 90 \\
ICD XIII Diseases of locomotor system & $16(11)$ & $11 \cdot 4(11)$ & 1.4 \\
ICD XVIII Accidents and violence & 0 & $3 \cdot 1(3)$ & \\
Other causes & $152(100)$ & $103 \cdot 1(100)$ & 1.5 \\
Total & & & \\
\hline
\end{tabular}

women, and $103 \cdot 1$ for both sexes (table 2). The overall mortality was thus 1.5 times higher in the patients with ankylosing spondylitis than in the general population of the same sex and age. There was an increasing disparity between the observed and expected number of deaths with time (figure), which indicates that mortality in ankylosing spondylitis is related to disease duration.

The mean decrease in survival of male patients with ankylosing spondylitis was 15 years (56.1 $v 71.5$ years) and of female patients with ankylosing spondylitis six years $(71 \cdot 1 v$ 76.9 years).

Half of the excess mortality was directly attributable to ankylosing spondylitis, as it was the underlying cause of death in 27 patients ( 0.3 expected for all diseases of the locomotor system). Excess deaths were also observed from circulatory, gastrointestinal and renal diseases, and from accidents and violence.

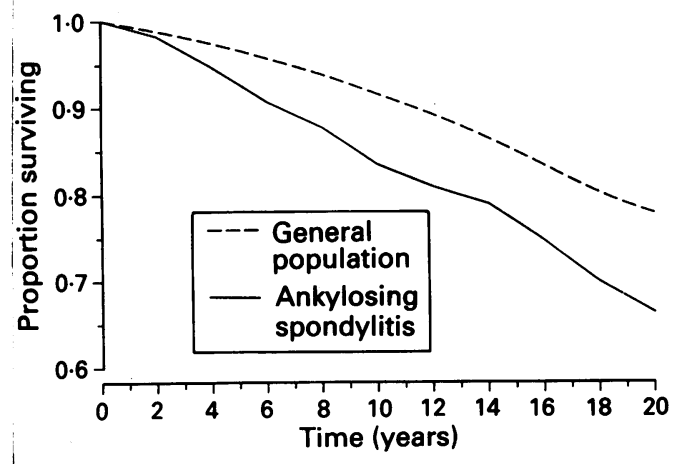

Cumulative survival of patients with ankylosing spondylitis and general population.

Table 3 Mechanisms of death directly connected with ankylosing spondylitis

\begin{tabular}{lc}
\hline Cause of death & No of subjects \\
\hline Secondary amyloidosis & 19 \\
Aortic insufficiency & 3 \\
Total atrioventricular block & 1 \\
Fracture of the spine & 1 \\
Cardiomyopathy & 2 \\
Ankylosing spondylitis & 1 \\
Total & 27 \\
\hline
\end{tabular}

Table 4 Comparison of living and dead patients. Values are mean (median)

\begin{tabular}{lll}
\hline $\begin{array}{l}\text { Characteristics at the beginning } \\
\text { of follow up }\end{array}$ & $\begin{array}{l}\text { Living } \\
\text { patients }\end{array}$ & $\begin{array}{l}\text { Dead } \\
\text { patients }\end{array}$ \\
\hline Age (years) & $32 \cdot 3$ & $43 \cdot 3^{\star}$ \\
Erythrocyte sedimentation rate & $38 \cdot 5$ & $54 \cdot 1^{\star}$ \\
$\quad$ (mm/hour) & & \\
Number of inflamed limb joints & $0 \cdot 7(0 \cdot 0)$ & $1 \cdot 5(1 \cdot 0)$ \\
Number of inflamed tendon & $0 \cdot 4(0 \cdot 0)$ & $0 \cdot 4(0 \cdot 0)$ \\
$\quad$ insertions & & \\
Serum protein (g/l) & $83 \cdot 3$ & $82 \cdot 0$ \\
Serum gammaglobulin $(\mathrm{g} / \mathrm{l})$ & $18 \cdot 0$ & $18 \cdot 5$ \\
Serum creatinine $(\mathrm{g} / \mathrm{l})$ & $84 \cdot 0$ & $89 \cdot 3$ \\
\hline
\end{tabular}

${ }^{\star} \mathrm{p}<0.001$.

Table 3 gives the immediate causes of death of those 27 patients in whom the underlying cause of death was ankylosing spondylitis. Nineteen patients died from secondary amyloidosis, six from cardiovascular complications, and one from fracture of the spine. The immediate cause of death was not documented in one patient. Table 4 shows that the patients who died were significantly older, and had a higher erythrocyte sedimentation rate and more inflamed limb joints than the surviving patients at the beginning of the follow up.

Cause of death was confirmed by necropsy or biopsy in $55 \%$ of patients, by appropriate laboratory investigations or electrocardiography in $4 \%$, by other hospital investigations including operation in $39 \%$, and by anamnestic information only in $2 \%$ of patients. Amyloid deaths were confirmed by necropsy or biopsy in $74 \%$ of patients. In $26 \%$ of patients the diagnostic method could not be verified.

\section{Discussion}

Ankylosing spondylitis is often a benign disease, and most patients probably never need hospital treatment. It is obvious that the life expectancy of these patients does not significantly differ from that of the general population. In patients admitted to hospital the clinical picture, and also the outcome, may be different. The disease can lead to severe disability, and continuous inflammation can cause systemic complications such as secondary amyloidosis and carditis. In addition, treatment of ankylosing spondylitis by drugs can cause serious side effects. Thus the outcome of patients admitted to hospital does not represent that of all patients.

The patients in this study represent the top of the pyramid, being patients from a national hospital for rheumatic diseases. The difference in the outcome between these patients and the general population is probably more pronounced than it would be if the patients were drawn from outpatient clinics. This patient population has one advantage (possible complications of ankylosing spondylitis can be identified) and one disadvantage (the results cannot be applied to all patients with ankylosing spondylitis).

Mortality during the 25 years was $38 \%$, which is similar to that in earlier studies. ${ }^{15-17}$ Secondary amyloidosis was the immediate cause of death in 19 patients $(13 \%$ of all deaths), which is clearly a higher figure than 
has been reported previously. ${ }^{3}{ }^{4}$ It is difficult to evaluate the reason for this difference. It may be partly due to classification differences. In some studies possibly only the underlying cause of death is mentioned, and the mechanism of death has not been evaluated. There may also be differences in patient populations, and the patient population in this study may be highly selective. Diagnostic practices may differ. There remains, however, a possibility that there are variations in the occurrence of secondary amyloidosis in different countries.

There is not much information available on the prevalence of amyloidosis in ankylosing spondylitis. In three British studies amyloidosis has been found to be a direct cause of death in six of 1582 , none of 1759 , and none of 146 patients with ankylosing spondylitis. ${ }^{3-5}$ In two Canadian studies the figures were one of 54 and one of 61 patients who died, ${ }^{6} 16$ and in a study from the USA no amyloid deaths were found among 22 patients with ankylosing spondylitis. ${ }^{15}$ Studies on living patients with ankylosing spondylitis have shown that the prevalence of amyloidosis in ankylosing spondylitis is $4-5 \%$ in West Germany, Yugoslavia, and France. ${ }^{11} 1317$ One explanation may also be that genetically determined susceptibility to amyloidosis or treatment plays a part.

The observed mortality was 1.5 times higher in patients with ankylosing spondylitis than in the general population. Excess deaths were mainly caused by ankylosing spondylitis itself, but circulatory, gastrointestinal and renal diseases, and violence also caused more deaths than expected. Cardiac disease is well known in ankylosing spondylitis, and characteristic complications such as aortic insufficiency, cardiomyopathy, and atrioventricular block were recorded as immediate causes of death. Coronary artery disease caused $60 \%$ of circulatory deaths, and cerebrovascular diseases $25 \%$. There were no bleeding or perforated ulcers among the deaths from gastrointestinal disease. Chronic glomerulonephritis was stated as having caused all four deaths from renal disease. It is not known whether there were any cases of amyloidosis among these patients. Malignant neoplasms were as common as expected, and there is probably no reason to suggest any difference in the occurrence of malignant diseases between patients with ankylosing spondylitis and the general population. One patient died from leukaemia and another from lymphoma.

Infections were recorded as an underlying cause of death in two patients, both of whom died from septicaemia, but infections may be more important because most infectious deaths are classified outside chapter I of the International Code of Diseases. A total of nine patients died from infections (five from pneumonia, two from septicaemia, one from infectious pericarditis, and one from infectious peritonitis).

It could be assumed that patients admitted to hospital are more likely to have two diseases than are patients not referred to hospitals. More than $90 \%$ of the patients in this study, however, presented with one diagnosis at their first admission to hospital. Thus it is not likely that the second disease could explain the increased death rate. In addition, excess deaths were mainly caused by ankylosing spondylitis itself (table 2).

Surprisingly, in an earlier epidemiological study ${ }^{18}$ the mortality of male patients with ankylosing spondylitis did not differ from that of control men, whereas the mortality of female patients with ankylosing spondylitis was double that of control women. A possible explanation might be that the study dealt with patients with ankylosing spondylitis diagnosed between 1935 and 1973. At that time probably only those female patients with ankylosing spondylitis with the most severe disease received a correct diagnosis of ankylosing spondylitis. It has commonly been thought that ankylosing spondylitis in women is often a mild disease, and for this reason it may be expected that the mortality of female patients is lower than that of male patients. The same observation could also be made in this study, with mortality of men $40 \%$ and mortality of women $26 \%$. Naturally, account must be taken of the fact that in this study the proportion of female patients was as low as $14 \%$, which probably means that the mildest forms of the disease in women have been missed.

The valuable contribution made by Hannu Kautiainen in the statistical analyses is gratefully acknowledged, as is that of Mauri Nieminen from the Central Statistical Office of Finland. This work was supported by a grant from the Rheumatism Research Foundation.

1 Blumberg B, Ragan C. The natural history of rheumatoid spondylitis. Medicine (Baltimore) 1956; 35: 1-31.

2 Wilkinson $M$, Bywaters $E$. Clinical features and course of ankylosing spondylitis as seen in a follow-up of 222 hospital referred cases. Ann Rheum Dis 1958; 17: 209-28.

3 Court-Brown W, Doll R. Mortality from cancer and other causes after radio-therapy for ankylosing spondylitis. $B M \mathcal{F}$ 1965; ii: $1327-32$.

4 Smith P, Doll R. Mortality among patients with ankylosing spondylitis after a single treatment course with X-rays. spondylitis after a single
$B M 7$ 1982; 284: 449-60.

5 Radford E, Doll R, Smith P. Mortality among patients with ankylosing spondylitis not given X-ray therapy. $N$ Engl $f$ Med 1977; 11: 572-6.

6 Kaprove R, Little H, Graham D, Rosen P. Ankylosing spondylitis. Survival in men with and without radiotherapy. Arthritis Rheum 1980; 1: 57-61.

7 Hart F D, Edin M. Ankylosing spondylitis. Lancet 1968; ii: $1340-4$.

8 Hart F D. Clinical features and complications. In: Moll J, ed. Ankylosing spondylitis. London: Churchill Livingstone, 1980: 52-68.

9 Calin A. Ankylosing spondylitis. In: Kelley W, Harris E, Ruddy S, Sledge C, eds. Textbook of rheumatology. Ruddy S, Sledge C, eds. Textbook

10 Cruickshank B. Pathology of ankylosing spondylitis. Bull Rheum Dis 1960; 10: 211-4.

11 Jayson M, Salmon P, Harrison W. Incidence of amyloidosis in ankylosing spondylitis. Rheum Phys Med 1971; 11: 78-82.

12 Christoph R, Genth E, Hartl W. Incidence of amyloidosis in ankylosing spondylitis [abstract]. Scand $\mathcal{f}$ Rheumatol Suppl 1975; 8: 39-04.

13 Mladenović V, Glisić L, Kerimović D, Arambasić B, Berovic $\mathrm{Z}$. Incidence of amyloidsis in rheumatoid arthritis and ankylosing spondylitis [abstract]. Scand $₹$ Rheumatol Suppl 1975; 8: 39-03.

14 Lehtinen K. Cause of death in 79 patients with ankylosing spondylitis. Scand $\mathcal{F}$ Rheumatol $1980 ; 9: 145-7$.
spond

15 Khan M A, Khan M K, Kushner I. Survival among patients with ankylosing spondylitis. A life-table analysis. $\mathcal{F}$ Rheumatol 1981; 8: 86-90.

16 Carette S, Graham D, Little H, Rubenstein J, Rosen P. The natural disease course of ankylosing spondylitis. Arthritis Rheum 1983; 2: 186-90.

17 Villiaumey J, Lejeune E, Avouac B, Horread P. Spondylarthrite ankylosante et amylose. Ann Med Interne (Paris) 1978; 129: 67-71.

18 Carter E, McKenna C, Brian D, Kurland L. Epidemiology of ankylosing spondylitis in Rochester, Minnesota, 1935-73. Arthritis Rheum 1979; 4: 365-70. 